\title{
An Android Application for Construction Management System Using GPS Tracking
}

\author{
Jesnamol Mathew ${ }^{1}$, Sreenimol K $\mathbf{R}^{2}$ \\ ${ }^{1}$ PG Student, Mangalam College of Engineering, India, jesnam1992@gmail.com \\ ${ }^{2}$ Associate Professor, Mangalam College of Engineering, India, sreenimol.kr@mangalam.in
}

\begin{abstract}
Construction management system is used for managing all activities for construction companies. It mainly includes all location based attendance marking system. Existing features of construction management system include record all activities in construction field, budget management facility etc. Construction management system using GPS tracking is an enhanced portable method for managing all activities including existing features and some additional features like tools and equipment management facilities, option for view employee pay slip, evaluating work progress in site.etc
\end{abstract}

Key words : Gps, webs vice, Retrofit, Mysql server, JSON data.

\section{INTRODUCTION}

Construction management system is an android application mainly aims for coordinating works for builders. It mainly aims for a portable attendance marking system along with location marking, which helps users to mark their attendance at worksite itself without coming to the office. Daily field reports are a more formal way of recording information on the job site. They contain information that includes the day's activities, temperature and weather conditions, delivered equipment or materials, visitors on the site, and equipment used that day. It consist of mainly two users project manager and site engineers. It consist of features like attendance marking with live location for site engineers, assign work to site engineers, assigning tools equipment and employees for different sites, updating the work at each site by uploading images, evaluate wok progress, track the daily expense, timely maintenance of buildings

\section{EXISTING SYSTEM}

Construction management system is an android application mainly aims for coordinating works for builders. Several programs are used in the management of construction projects at all stages, from planning and designing to final delivery [3]. It also facilitates and accelerates the process of communication between the employees in the site and the decision's maker in order to make the necessary corrections or modifications.different sites, updating the work at each site by uploading images, evaluate wok progress, track the daily expense etc.[1].The main three pillers of construction management system are time, cost and quality[2]. By using computer and information technology we can reduce the management cost, with an effective time management facility. The enterprise business information management and enterprise resource management are used to support Web service and XML, as well as the application of cross operating system in multi-database system, using business process control management as the core[4].

\section{PROPOSED SYSTEM}

In the proposed system, it has some features for attendance marking facility using google positioning system for site engineers. In construction field, site engineers needs to work at different sites at different time. In that case their check -in and check -out can facilitates by gps location mechanism. Project manager assign work to site engineers with the exact location of the site. Each site engineers can view the list of sites they must visit. When they reached at the site ,they can check in by using the location. The check-in facility is only active if they are at few meters from exact location marked by the project manager during assign of task. During check-out time they can upload the work status of the particular site by uploading the images from site. The project management maturity model (PM3) has become an attractive technique of project management in many industries, yet there are hardly applications of PM3 in construction industry[6].

The project manager can track the time spent by each site engineers at the location. Thus it facilitates an effective management system for construction companies. Another feature of this project is to track the work status of each site. It consists of tools and equipment management facility. Tools and equipment management facilitates an effective method for managing the tools, vehicles like cranes etc for different sites. Each site engineers can request for the tools, materials for the site work. During the inspection time of site engineers, they gather the information regarding requirements for the work site and sent the requirement for project manager. 
Project manager can verify the requirements and grant permission for collecting the materials required. Construction is one of the most hazardous industries because it involves dynamic interactions between workers and machinery on sites[5].

\section{Google positioning system}

Google positioning system is used for location the check-in location. During check-in time the latitude and longitude for site engineers live location is sent to the server along with the login time. The login time is time taken from server. GPS uses a lot of complex technology, but the concept is simple. The GPS receiver gets a signal from each GPS satellite. The satellites transmit the exact time the signals are sent. By subtracting the time the signal was transmitted from the time it was received, the GPS can tell how far it is from each satellite. The GPS receiver also knows the exact position in the sky of the satellites, at the moment they sent their signals. So given the travel time of the GPS signals from three satellites and their exact position in the sky, the GPS receiver can determine your position in three dimensions - east, north and altitude. There is a complication. To calculate the time the GPS signals took to arrive, the GPS receiver needs to know the time very accurately. The GPS satellites have atomic clocks that keep very precise time, but it's not feasible to equip a GPS receiver with an atomic clock. However, if the GPS receiver uses the signal from a fourth satellite it can solve an equation that lets it determine the exact time, without needing an atomic clock. If the GPS receiver is only able to get signals from 3 satellites, you can still get your position, but it will be less accurate.

As we noted above, the GPS receiver needs 4 satellites to work out your position in 3-dimensions. If only 3 satellites are available, the GPS receiver can get an approximate position by making the assumption that you are at mean sea level. If you really are at mean sea level, the position will be reasonably accurate. However if you are in the mountains, the 2-D fix could be hundreds of meters off.

A modern GPS receiver will typically track all of the available satellites simultaneously, but only a selection of them will be used to calculate your position. Conserving mobile device energy would make the underlying chips and hardware more efficient. Algorithmic solutions that use those resources wisely without wasting energy for positioning extends device usage time[8].

\section{Web services}

Android apps uses web service to access MySql database. There are mainly 2 types of web services used for access ,RESTFUL and SOAP. Restful web service is more ease of use than SOAP.SOAP web service is more secure than REST but compare to the data retrieval speed REST is faster than SOAP web service. We can user volley libraries, OK HTTP methods for web service call. Comparing to the existing features we introduce a new library called Retrofit for fast retrieval of data. In our case fast retrieval is adequate than security so we use Retrofit library for fast retrieval of information in low speed networks.

\section{Retrofit}

Retrofit is the REST client for Java and Android. It makes it relatively easy to retrieve and upload through REST based web service. In most cases, server request and responses are mapped to a language independent format called JSON format. Serialization and Deserialization of JSON data is necessary while using Retrofit library. The REST (Representational State Transfer) has become the most commonly used way for creating, publishing, and consuming Web services, exploiting JavaScript Object Notation (JSON) as a data exchange format. Android Volley and Retrofit are the most used libraries for accessing the REST Web APIs today[7].

\section{Mysql database}

MySql database is the database used for store and retrieval of data.

\section{SQLite database}

Application login credentials like username, password etc can be stored in device database. SQLite is the local database used in android phones. Only a few data type is supported in Sqlite database examples are TEXT, REAL, INTEGER, BLOB. Images are stored as BLOB data.

\section{Google Map API}

Google map API integration is used for finding the location of the user.

\section{Firebase Cloud messaging}

Firebase cloud messaging is used for send message to all app users. By using this feature the project manager can able to sent messages regarding the meetings organized in the company.

\section{SYSTEM ARCHITECTURE}

The proposed architecture is designed with the functions given as in figure 1 . When site engineers reach at the site they first call the login web service. Login web service grant permission for login for each app user based on some criteria .Web services have accesses to database. Web services are resides in web server. The app user must turned $\mathrm{ON}$ the location facility in their android phones before accessing the web server. Admin or project manager can able to login from admin panel and can able to send messages for all app users 
by Firebase cloud messaging facility. Figure 2 shows the home page layout of the android application developed for the construction management.

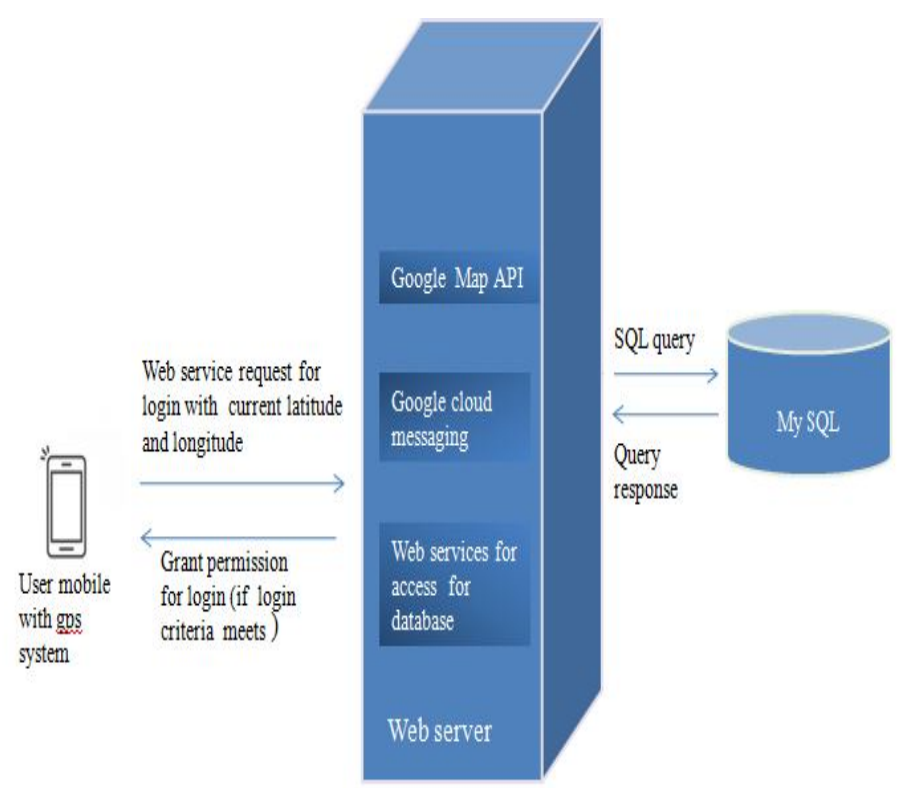

Figure 1: System architecture

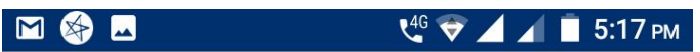

Construction Management System

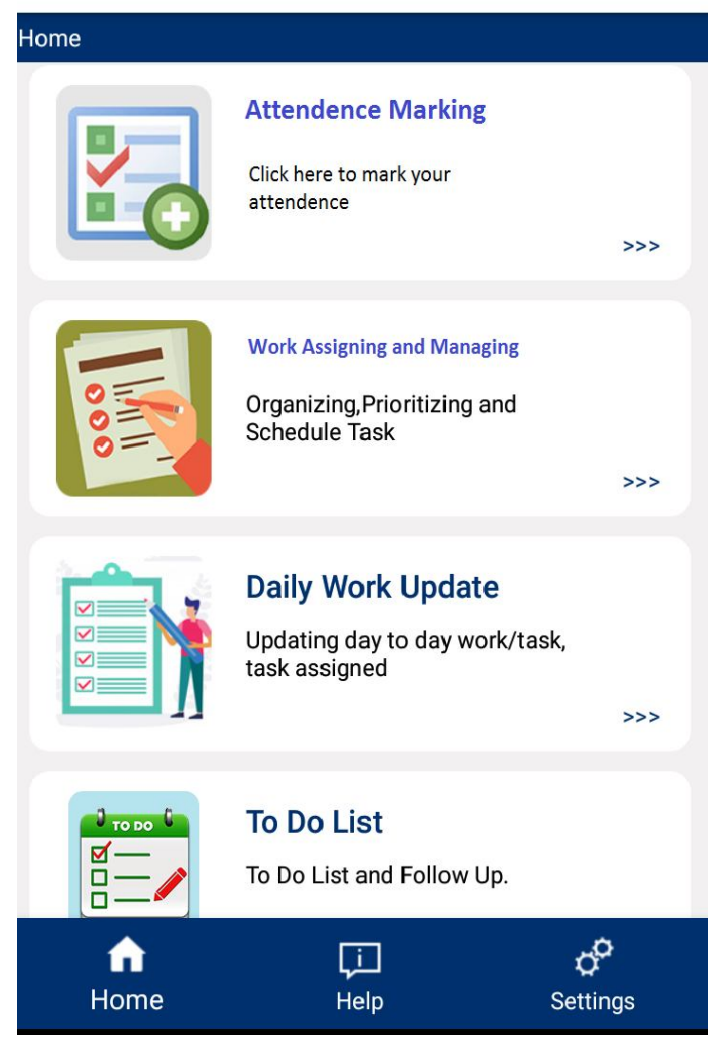

Figure 2: Home Page- Layout

\section{CONCLUSION}

Comparing to the existing features in construction management system our technology is more reliable and useful. This application with latest technology can be easily implemented easily and can manage easily. Moreover the gps based attendance marking is also useful for employees which helps to reduce time and cost of travelling. It helps to manage equipments, tools ,cranes used in different sites in an efficient way.

\section{REFERENCES}

1. Bi-Wen Lee, Hsin-Yi Shih, Yu-Tuan Chou and Yu-Sin Chen. Need Analysis of Building Maintenance: A Case Study in Small-scale Residential Buildings Based on the Perceptions of Construction Industry, 2017 International Conference on Information, Communication and Engineering (ICICE), October 2018.

2. Sarah Nazar Dheyab. Electronic Management In Construction Projects, IEEE conference, May. 2018.

3. P. Mesaroš , T. Mandi_ak, M. Vukomanovi and S. Kolari Comparison of BIM education process in construction management field at Technical University of Košice and University of Zagreb, IEEE International Conference on Emerging eLearning Technologies and Applications, Nov 2018.

4. Chen Haojie. Design and Implementation of Construction Engineering Business Management System, International Conference on Smart Grid and Electrical Automation, Nov 2017 https://doi.org/10.1109/ICSGEA.2017.103

5. Muhammad Arslan, Christophe Cruz, Dominique Ginhac. Understanding Worker Mobility within the Stay Locations using HMMs on Semantic Trajectories, 14th International Conference on Emerging Technologies (ICET), Nov 2018. https://doi.org/10.1109/ICET.2018.8603666

6. Zhai Fengyong, Liu Renhui. Study on Framework of Construction Project Management Maturity Model, 2007 International Conference on Service Systems and Service Management, July 2007. https://doi.org/10.1109/ICSSSM.2007.4280298

7. Mohamed Lachgar,Hanane Benouda,Selwa Elfirdoussi. Android REST APIs: Volley vs Retrofit, 2018 International Symposium on Advanced Electrical and Communication Technologies (ISAECT),Jan 2019. https://doi.org/10.1109/ISAECT.2018.8618824

8. Yunus Ozen,Oguzhan Ozdemir,Necla Bandirmali. Android based energy aware real-time location tracking system, 2015 Seventh International Conference on Ubiquitous and Future Networks,Aug 2015. https://doi.org/10.1109/ICUFN.2015.7182662 